\title{
Risk Manage Capital Investment Decisions: A Lease vs. Purchase Illustration
}

Thomas L. Zeller, PhD., CPA, Loyola University Chicago

Brian B. Stanko, PhD., CPA, Loyola University Chicago

\begin{abstract}
This paper demonstrates how to build risk into capital investment decisions. We illustrate how to combine distribution theory, technology, and a business professional's skills and insight into a capital investment analysis. In addition, we show how management can approximate the risk of each cash flow estimate and display the overall capital investment results. This framework is extended by showing how a mutually exclusive decision can be improved, using a lease versus purchase example. ${ }^{a}$ An Excel template is readily available from the authors allowing a hands-on application of the framework presented in this paper. In addition, this paper positions the reader to comfortably use more advanced analytics, such as Monte Carlo simulation, a tool that is readily available in commercial software applications.
\end{abstract}

Keywords: capital budgeting, Monte Carlo simulation, risk management, lease versus purchase, Risk, simulation, lease vs. buy, capital budgeting, capital investing

\section{INTRODUCTION}

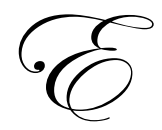

xternal and internal business issues continually challenge the seasoned professional when making capital investment decisions. The need to anticipate external market changes, such as, competitor response, environmental uncertainties, political interruptions, technology changes and more, require management to blend art and science in the decision making process. ${ }^{1}$ Will technology change, and make this investment obsolete in year two of a five-year investment decision? Will a competitor surface out of the international marketplace and make the current investment no longer financially productive?

Internal challenges force management to blend science and art in making a capital investment decision as well. Lack of comparable options, data bias (optimism/pessimism), managerial talent, and acceptance to change by the workforce, are all unknown conditions that management must consider when making a capital budgeting decision. $^{2}$ These and many other market changes can disrupt the projected cash flows of a capital investment decision. Yet, management must use the best information available to project cash flows and make appropriate capital investment decisions to increase shareholder (owner) wealth.

Capital budgeting decisions are among the most important choices leadership makes for a business enterprise to increase shareholder value. ${ }^{3}$ The decisions commit substantial resources for an extended time. Leadership must make the correct investment decisions to support the overall corporate, business and functional level strategies to improve its opportunities for success. ${ }^{4}$ Proper capital investment decisions drive financial performance and growth. Management must replace assets and purchase new assets to support a business's strategic plan. Both types of investments are essential to create value for the business owner(s) or shareholder.

\footnotetext{
${ }^{a}$ This paper focuses on the application of net present value. The advantage of using net present value in a capital budgeting decision is that it shows the potential stakeholder wealth creation and wealth destruction. An internal rate of return analysis is intentionally left out of this paper. According to Brealey, Myers and Allen, Principles of Corporate Finance, New York, NY: McGraw-Hill/Irwin 2006, pp. 91-99, internal rate of return should not be used to evaluate mutually exclusive capital investments.
} 
Traditional approaches to managing risk in a capital investment analysis are helpful but limited. The longstanding approach to increasing the discount rate to adjust for risk simply requires a greater cash flow somewhere along the timeline to guarantee a project's positive NPV. In this situation, management models the risk associated with the many cash flow estimates with one risk-adjusted discount rate. Critical thinking, however, begs the question: Is it reasonable to capture the risk of the many cash flow estimates by increasing or decreasing one value, the discount rate? "What-if" analysis in the traditional framework is helpful, but limiting, when modeling selective cash flow assumptions. Regardless of how values are changed, these methods still leave the accounting or finance professional with only one or a select few net present value (NPV) estimates in support of the capital decision. Is it reasonable to provide an exact NPV estimate to management? Providing one estimate masks risk leaving the art side of a capital investment decision to gut feel and good fortune. Using gut feel and good fortune are always necessary in business. Yet, critical analytical tools can improve gut feel necessary with a capital investment decision.

Needed is a method to evaluate risk in a capital investment decision. The analyst needs to see a range of possible NPV outcomes on a capital investment analysis. Beyond, the analyst needs a method to compare and contrast across a mutually exclusive investment decision. That is, how does the risk of one decision compare with the risk of another in a mutually exclusive investment decision?

Reasonable and practical methods exist to address the limitations of traditional capital budgeting. First, this paper shows how basic distribution theory tools can be used to link theory to practice in a capital budgeting decision. Second, this paper provides an Excel structure showing how to build risk into a capital budgeting analysis and applies distribution theory to show a range of NPV outcomes. The result is a visual range of possible NPV outcomes that are readily comparable across alternative capital investment decisions. The distribution shows capital investment risk in a picture, ultimately improving the analytics of a decision.

\section{DISTRIBUTION THEORY}

There are two important measures in a practical application of distribution theory: mean and standard deviation. Mean represents the summation of all possible values in the population (sample) divided by the population (sample) size. Standard deviation represents the square root of the variance (Variance is the sum of the squared difference between the mean and each value in the population (sample) divided by the population (sample) size.). Distribution theory becomes a practical analytical tool when a mean and standard deviation can be reasonably estimated. An Excel spreadsheet template, discussed later in this paper, shows how to capture the mean and standard deviation data points and incorporate them into a capital budgeting analysis.

A discussion of distribution theory naturally begins with a reference to a normal distribution. The normal distribution is represented with a bell shaped curve and is the most popular of all distributions. Figure 1 represents an example of a normal distribution. The space under the curve is actually a measure of area. Think about this area as all the possible NPV outcomes that could result with the many different combinations of cash flows. The height of the curve represents the frequency of a particular NPV outcome, similar to a histogram.

The height and spread of the normal distribution is determined by the frequency of possible NPV outcomes in a capital investing analysis. A very high and tight looking normal distribution represents a set of NPV outcomes very close to the mean NPV. This type of distribution for capital investment analysis represents limited risk because the range of NPV outcomes is reasonably narrow. A wide and flat looking distribution represents a set of NPV outcomes not very close to the mean. This type of distribution in a capital investment analysis represents high risk because the range of NPV outcomes is reasonably wide, spread away from the mean. Thus, a narrow distribution of NPV outcomes signals limited risk and a wider distribution of NPV outcomes signals greater risk in a capital investing decision. Putting risk into a visual picture helps the business professional apply science and gut feel in the capital investment decision-making process.

Distribution theory tells us that approximately $99 \%$ of the area under a normal distribution curve falls within three standard deviations from each side of the mean. Figure 1 represents a normal distribution curve, marked with three standard deviations. Distribution theory also tells us that one standard deviation from the mean in 
an approximately normal distribution represents $34 \%$ of the area from the mean. Thus, one standard deviation on each side of the mean represents approximately $68 \%(34 \%+34 \%)$ of the area under the normal distribution curve. Two standard deviations from the mean of an approximately normal distribution represent $48 \%$ of the area from the mean. Thus, two standard deviations on each side of the mean represent approximately $96 \%(48 \%+48 \%)$ of the area under the normal distribution curve. Three standard deviations from the mean of an approximately normal distribution represent slightly more than $49 \%$ of the area from the mean. Thus, three standard deviations on each side of the mean represent approximately $99 \%$ of the area under the normal distribution curve.

Building upon this insight about distribution theory, it is possible to generate better information from a range of net present value outcomes, i.e., link theory to practice (Later in this paper we show how to easily generate the necessary values for using distribution theory in a Excel template.). For now assume in a capital investment analysis we know the approximate worst case NPV scenario is $(\$ 79,000)$ and a best case NPV scenario is $\$ 149,000$. These NPV estimates represent the approximate extreme outcomes from a capital investment decision. Another way of interpreting this would be to say that the range from the best case to worst case NPV outcomes represent approximately $99 \%$ of the area under the normal distribution curve, or 3 standard deviations from each side of the mean.

Now we can estimate a mean NPV as follows:

a) Compute the range (the range between $\$ 149,000$ and $(\$ 79,000)$ is $\$ 228,000$ ).

b) Divide the range by 2 (dividing the range by 2 is equal to $\$ 114,000$ ).

c) Estimate the mean by adding the result from $\mathrm{b}$ above to the worst case or subtracting the result from the best case (adding $\$ 114,000$ to $(\$ 79,000$ ) equals $\$ 35,000$ or subtracting $\$ 114,000$ from $\$ 149,000$ equals $\$ 35,000$.).

Next, we can estimate the standard deviation. Distribution theory tells us that the range between the best case and worst case scenario is 6 standard deviations as discussed above (three standard deviations on each side of the mean of an approximately normal distribution) as represented in Figure 1. Extending the example from above, one standard deviation from the mean is $\$ 38,000$ ( $\$ 228,000$ by 6 ).

Now we can provide the user with valuable insight to support the gut feel that is always necessary in a capital investing decision. See Figure 2. By adding and subtracting one standard deviation of $\$ 38,000$ to and from the mean of $\$ 35,000$ produces a range of $\$ 73,000$ to $(\$ 3,000)\{\$ 35,000+,-\$ 38,000\}$. This means that the analysis shows capital investment NPV to be approximately $\$ 35,000$, with $68 \%$ of all possible outcomes in a range between $(\$ 3,000)$ to $\$ 73,000$.

The discussion illustrates a practical application of distribution theory in a capital budgeting analysis. A distinct benefit to this information is that the consumer of the NPV analysis can clearly see a range of possible outcomes with specific parameters provided by a practical application of distribution theory. The output shows capital investment risk in a picture improving the analytics of a decision. The mean represents the accountant's best judgment in a traditional capital investing analysis situation. Basic distribution theory enriches the analysis by providing a range of possible outcomes with supporting percentages of possible NPV estimates. The model makes explicit the risk of a capital investment decision. Next, we show how to build distribution theory into a capital budgeting analysis using the above discussion and adding the complexity of evaluating two mutually exclusive investment options.

\section{A PRACTICAL ILLUSTRATION OF BUILDING RISK INTO A CAPITAL EXPENDITURE DECISION}

Most often the capital investment decision comes down to an "it depends." In other words, the decision depends upon how management believes the many variables and assumptions will ultimately play out. Assumptions and estimates regarding sales, maintenance costs, residual values, competitor response, software update costs, and more, are typical issues that arise. 
A practical solution is to build risk into each cash flow estimate. This can be accomplished by assigning a best case and worst case weight to each cash flow estimate. Table 1 - Weighting Demonstration provides an illustration. The table shows an initial investment and cash flow estimates in year 1 and year 5 with each cash flow estimate weighted for a best case and worst case scenario. The dollar values in Table 1 represent the analyst's estimated cash flows based on the traditional study and evaluation that goes into a capital investment analysis. The best and worst case weights in the shaded areas represent the subjective opinion of the analyst for each cash flow estimate, assuming the best possible situation and the worst possible situation.

Presented below are the analytics behind this structure. (See Table 1)

1. Starting with the initial estimated purchase amount of $\$ 77,500$, best case and worst case weights are assigned .95 and 1.1. This means that the analyst estimates from traditional study and evaluation that the equipment will cost $\$ 77,500$. Next, under a best case scenario, driven by discounts or other purchase savings at the time of purchase, the equipment will cost approximately $95 \%$ of the $\$ 77,500$. Last, under the worst case scenario, driven by additional costs at the time of purchase, the equipment will cost approximately $110 \%$ of the $\$ 77,500$.

2. Initial investment costs, labeled "site preparation" and "training", are also weighted. The analyst estimates from available data that the site preparation and training costs will be approximately $\$ 10,000$ and $\$ 5,000$ respectively. However, the best case scenario is that it will cost less than $\$ 10,000$ to prepare the site, represented with a weight of .8 , and training will cost less than $\$ 5,000$, represented with a weight of .9 . The worst case scenario for each cost is also estimated with weights of 1.3 and 1.1, respectively.

A similar pattern of thinking is applied to the many estimates of future cash flows. The software update and maintenance cash flow estimates, under the recurring cost section of Table 1 can be used to illustrate this application. The early years of projecting cash outflows for software update and maintenance may be reasonably straight forward. As a result best case and worst case weights are set at 1.0. This means the analyst is certain that this will be the cost. Such certainty is drawn from a signed contract or some other source that provides evidence of the specific cost.

Estimating these costs five years into the future may be a very difficult task. As such, providing a range to estimated cash outflows is a much more logical approach in a NPV analysis. Building the risk into these estimates is reflected with weights of less than 1.0 for the best case scenario and greater than 1.0 for the worst-case scenario in year 5 on Table 1. Observe in year 5 the best and worst case weights range from .8 to 1.3 for software update in this illustration.

Undoubtedly, the effort to weight estimated cash flows carries professional subjectivity. The analyst must take the knowledge and insight accumulated in building a point estimate and think about possible best case and worst case outcomes. Logically, no two professionals will come up with the exact weighting. The lack of exacting precision is not important. What is important is an approximation of the range of possible NPV outcomes, similar to Figure 2.

At this point commercially available software running Monte Carlo simulation takes over. The user needs to specify an estimated cash flow and the best and worst case estimates. The software allows the user to specify many different cash flow distributions. Commercially available software runs the Monte Carlos simulation from this point. The software provides a distribution of NPV outcomes, the essential output for a capital investment decision. The authors provide an Excel template that approximates the distribution output to show how capital investment analysis improves with the application of Monte Carlo simulation.

The output from this approach to capital budgeting provides the accounting or finance professional two very valuable tools. First, he/she can easily work with the many estimates and adjust for risk. Cash flow estimates with greater uncertainly and risk can be weighted with a wider range of possible outcomes. Thus, when presenting the results or when discussing one on one with colleagues, the capital investment risk becomes an integral component of the evaluation process. Second, distribution theory can be applied to the NPV outcomes providing a 
picture with associated percentages of where the NPV values fall within ranges around the mean. Risk becomes visible. This is valuable insight when comparing one mutually exclusive investment opportunity to another.

\section{THE LEASE VS. PURCHASE DECISION: AN ILLUSTRATION ${ }^{b}$}

The case that follows focuses on whether a company should lease (via an operating lease agreement) or purchase a piece of medical equipment. A working Excel file that supports the following discussion is available at: http://www.luc.edu/faculty/tzeller/risk_manage.shtml. The file consists of the following worksheets, all cell referenced off the 'Lease Data Section' and 'Purchase Data Section' worksheets.

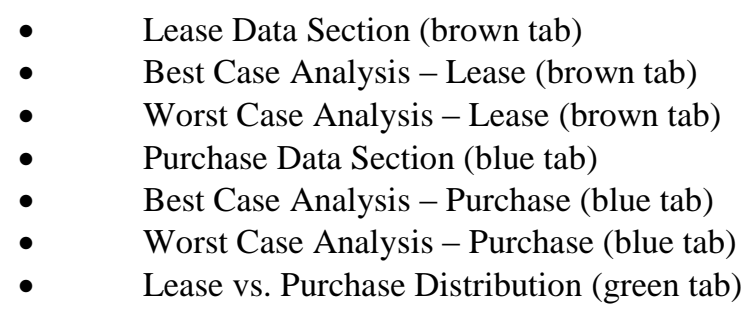

The many different types of lease contract elements, such as early cancellation, transfer of title, renewal options, and bargain purchase price (issues to consider when distinguishing capital leases from operating leases) are not built into this case. The authors have limited the components of the case to focus the discussion on distribution output and analysis.

Discussed below is the logic behind the lease versus purchase analysis. Table 2 illustrates the framework for the lease component of a lease vs. purchase decision, showing the initial outlay costs and years 1 and 5 cash flow estimates. Open the Excel worksheet titled 'Lease Data Section' to observe all 5 years. Many of the cash outflows for a lease contract are governed by the contract terms of the lease agreement. Having a detailed contract for a lease offers a distinct advantage to the lessee in knowing the cash outflows with certainty.

Table 3 illustrates the framework for the purchase component of a lease vs. purchase decision. Open the Excel worksheet titled 'Purchase Data Section' to observe all 5 years. In a purchase capital situation, however, management is responsible for many of the cash expenditures, therefore increasing the risk of a purchase. This situation makes estimating the cash outflows a distinct challenge in many situations. Our demonstration considers a lease contract that includes site preparation, employee training, software update, and maintenance estimates. A comparison and contrast follows with a focus on issues that require an analyst to weight cash outflows.

The row labeled "site preparation" in Tables 2 and 3 point to the first illustration. For a medical equipment lease, Table 2, the $\$ 50,000$ cost is not weighted. A lessor is typically involved in the site preparation to be certain the necessary infrastructure is in place and working properly. Risk is removed for the lessee because the lessor holds institutional knowledge about contractors, economies of scale, planning and preparing the site for the new equipment. The lessor understands how to efficiently and effectively get the equipment up and running and identify the specific site preparation cost for the lessee. A buyer of the equipment, Table 3, may not have the necessary institutional knowledge to know with precision all that is involved with site preparation and related costs. There is cost associated with learning and this uncertainty is reflected in Table 3 with a best case weighting of .9 and a worst case weighting of 1.1 for the site preparation estimate. This weighting reflects the risk associated with a purchase decision. The accounting professional can easily adjust the weights in the 'Purchase Data Section' worksheet simply by changing the weights in cells $\mathrm{C} 12$ and $\mathrm{C} 13$. (We discuss the output analysis in the next section.)

A similar argument can be applied to the row labeled training in Tables 2 and 3. Learning to operate and read the output from sophisticated medical equipment is not a trivial task. This illustration assumes that the training cost is set in the medical equipment lease contract at $\$ 5,000$, Table 2. For the lease, it is assumed the lessee is

\footnotetext{
${ }^{\mathrm{b}}$ We have elected to illustrate this concept with a lease versus purchase demonstration. The analytics, however, apply to any type of capital investment decision.
} 
carrying the full risk of training and specifies in a contract that the training fee will be $\$ 5,000$. Therefore the best case and worst case scenario weights are set at 1.0. This is not the case for training in the purchase illustration, Table 3. Here the weights are .9 for the best case and 1.1 for the worst case, reflecting that the buyer carries additional risk with the training component of the medical equipment purchase. The medical staff may not need all the necessary training or they may need more training.

Next, Tables 2 and 3 have a row labeled "software up-date." The medical equipment industry is driven by technological advancement and improvements in medical science. The two work hand-in-hand. As medical science advances, technology plays a role in knowledge application. As technology advances, new doors are opened for the application of medical science. Therefore, software updates in medical equipment are essential components of the lease vs. purchase decision.

Table 2 shows that the cash flow estimate for software update in year 5 is weighted .9 for the best case and 1.1 for the worst case scenarios. With these weights the lessor is effectively signaling that advances in medical science and technology are very difficult to predict. The lessee is sharing this risk within a limited range of cash outflows. Table 3, however, reflects a greater risk for the purchaser of the medical equipment in this illustration. The best case scenario is weighted .7 and the worst case is weighted 1.3 in year 5 . In reality, the range of cash outflows may be more significant, depending upon the potential changes in technological and scientific advances for software and hardware updates.

A similar argument is applicable to the cash flow estimate for "maintenance" costs, shown in Tables 2 and 3. The lessee is sharing the risk associated with maintance costs in lease 5, illustrated by a weighting of .9 for the best case and 1.1 for the worst case scenario, Table 2. The purchaser is assuming a greater risk, however, illustrated by a weighting of .7 for the best case and 1.3 for the worst case scenario, Table 3 . A greater risk in training appears reasonable with the challenges of predicting advances in technology and medical science.

Last, the row labeled "terminal value" in Table 3 represents another important estimate in the medical equipment lease vs. purchase decision. Ultimately, the terminal value of medical equipment is driven by its use, changes in technology and advancement of medical science. Therefore, terminal value estimates associated with medical equipment are very difficult to predict. Analysts can compensate for this level of uncertainly in the NPV analysis with a 1.2 weighting of the best case and a 0.5 weighting of the worst case estimated cash inflow, as illustrated in Table 3. In a lease contract terminal value can be specifically defined, which would result in a weight of 1.0 for the best and worst case scenario, Table 2.

\section{A PRACTICAL APPLICATION OF DISTRIBUTION THEORY}

An application of distribution theory is very useful in a capital investment decision. Figure 3 illustrates a range of NPV outcomes for a lease versus purchase capital investment analysis. Open the 'Lease vs. Purchase Distributions' workbook in the Excel file to view the same chart as shown in Figure 3. The illustration shows a direct comparison of a range of possible NPV values. The estimated mean cost for the purchase of the medical equipment is approximately $\$(589,993)$ and the mean cost for the lease is approximately $\$(569,942)$. These estimates would be the respective NPVs had a traditional NPV analysis alone been run on the capital investment decision.

However, much greater insight is available with a practical application of distribution theory. If we consider the purchase option one standard deviation ${ }^{\mathrm{d}}$ on each side of the mean, then we see NPV estimates of $\$(604,521)$ to $\$(575,465)$. This finding suggests that there is a $68 \%$ probability that the NPV of the purchase option

\footnotetext{
${ }^{c}$ The tables are truncated at years 1 and 5 to show the dynamics of this component when considering a medical equipment lease vs. purchase decision. The respective workbooks show all five years for each alternative.

${ }^{\mathrm{d}}$ We suggest keeping the analysis within one standard deviation from the mean. It is unlikely all of the best case or all of the worst case estimates with materialize over the life of an investment. A reasonable estimate is that some best case and some worst case scenarios will materialize over the investment period.
} 
will fall within this range. If we consider the lease option, one standard deviation on each side of the mean, then we see NPV estimates of $\$(574,950)$ to $\$(564,934)$. This finding suggests that there is a $68 \%$ probability that the NPV of the lease option will fall within this range.

An overlay of one NPV distribution over the other provides great insight into a capital investment decision. Figure 3 shows the risk of the lease is less than the risk of a purchase. The NPV range in the lease option at one standard is $\$ 10,016[(574,950)-(564,934)]$. The NPV range in the purchase option at one standard deviation is $\$ 29,056[(\$ 604,521)-(\$ 575,465)]$. The conclusion from this presentation is that leasing carries less risk in this illustration. In addition, the distribution overlays show the NPV range for the lease is to the right of the NPV range for the purchase. This suggests that even if costs increase for the lease, the overall result is likely to be much less than if the costs of purchasing are on target or slightly lower than expected. (Note: the chart is set-up to read decreasing costs moving left to right.) Observe that at one standard deviation to left of the lease option, a cost of $(\$ 574,950)$ is less than the purchase mean cost $\$(589,993)$. Therefore, Figure 3 presents a picture in support of the gut feel estimates that are necessary for a lease vs. purchase decision and, ultimately, improves the analytics in a capital investment decision.

In conclusion, it is clear in this example that management should lease the equipment. The lease option is less costly and carries less risk. The expected NPV of the lease is $(\$ 569,942)$ compared to the purchase option at $(\$ 589,993)$. The risk signal is read by the narrow distribution of the lease option compared to the wider distribution of the purchase option. The narrow distribution signals less risk in this capital investment decision.

You can use the spreadsheet to observe how changing weights changes the distribution of the lease vs. purchase option. With the Excel file open split the screen and open the 'Purchase Data Section' and 'Lease vs. Purchase Distribution' worksheets. ([Microsoft Excel 2007] With the 'Purchase Data Section' worksheet open, select View, Arrange All, Vertical. Open the 'Lease vs. Purchase Distribution' worksheet in the right-hand side window.) With both worksheets open, change cells M21 and N21 to .7 and 1.4, respectively in the 'Purchase Data Section' worksheet. Observe the Purchase option distribution in the chart shown in the 'Lease vs. Purchase Distribution' becomes wider. The overall distribution becomes wider when the range of possible outcomes becomes wider. Now change back to the original spreadsheet values. Observe the distribution becomes narrow when the range of possible outcomes becomes narrow. Spend time changing other weights to gain a general feel for how changing weights changes the respective distribution.

Applying distribution theory with capital budgeting analysis in practice is very simple. Commercial software is readily available for running Monte Carlo simulation. The software provides flexible input options for the distribution of each variable, NPV distribution analysis and more. Such insight shows the accounting and finance professional the specific variables that require special attention in a capital investment analysis.

\section{CONCLUSION}

This article helps an accounting or finance business professional manage risk in a capital investment decision. First, this article shows how distribution theory provides a range of NPV estimates. Next, this article shows how to build risk into the analytic process of a capital investment decision. Suggested is a weighting of each cash flow estimate. Using a medical equipment lease vs. purchase decision as an example, this paper shows how a graph of the NPV distributions signals risk and the relative range of possible outcomes of one decision over another. The result, the "it depends" approach to a mutually exclusive capital investment decision improves. Risk becomes explicit. Capital investment decisions challenges become manageable.

\section{AUTHOR INFORMATION}

Thomas L. Zeller, Ph.D., CPA, is a Professor of Accounting in the Department of Accounting and Business Law at Loyola University Chicago. He has published numerous articles and books. His research appears in a wide variety of academic and practitioner journals, including Strategic Finance, Journal of Accounting and Public Policy, Business Horizons, Healthcare Financial Management, and Issues in Accounting Education.

Routinely he presents to professional groups on topics addressing financial analysis, activity-based costing and business measurement. He teaches graduate and undergraduate level courses in accounting at Loyola. He is 
actively involved as a Center for Corporate Financial Leadership (CCFL) teaching seminars in financial measurement and capital budgeting. He is a member of the American Accounting Association, Illinois CPA Society and American Institute of Certified Public Accountants.

Brian Stanko, Ph.D., CPA. Professor Stanko received a B.S. and M.B.A. from Eastern Illinois University and a $\mathrm{Ph} . D$. in Accounting from the University of Kentucky. He is currently Department Chair and MSA Program Director at Loyola University Chicago. Professor Stanko's primary research and writing interests concern financial reporting standards and the understanding of corporate annual reports. He is the coauthor of three books and has published articles in The Journal of Accounting and Public Policy, Issues in Accounting Education, Corporate Controller, The Government Accountants Journal, Strategic Finance, Journal of Business Ethics, The CPA Journal, and International Advances in Economic Research. Professor Stanko's teaching responsibilities include principles, intermediate, and graduate level accounting courses.

Figure 1: Practical Distribution Theory Insight

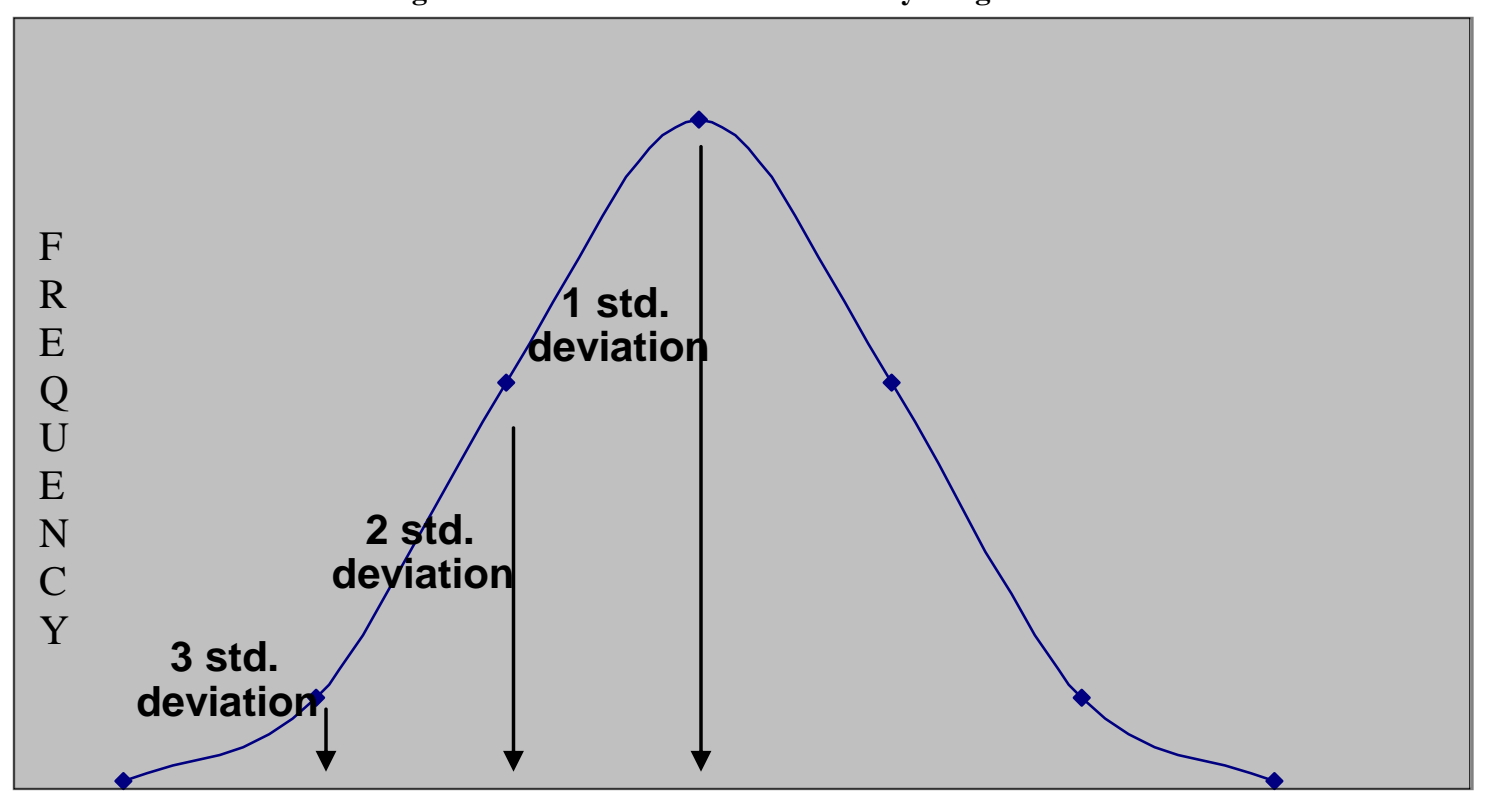

Figure 2: Distribution Theory Number Example

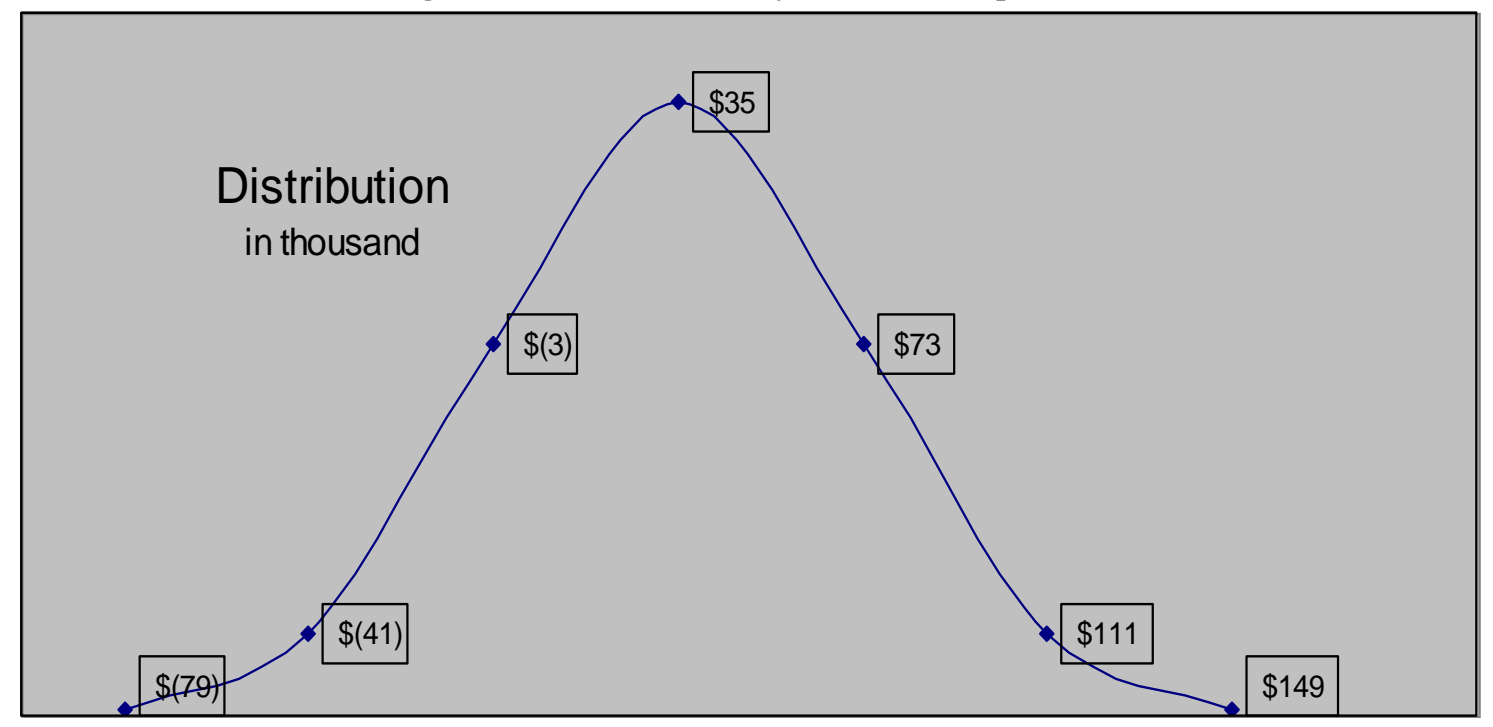


Table 1: Weighting Demonstration

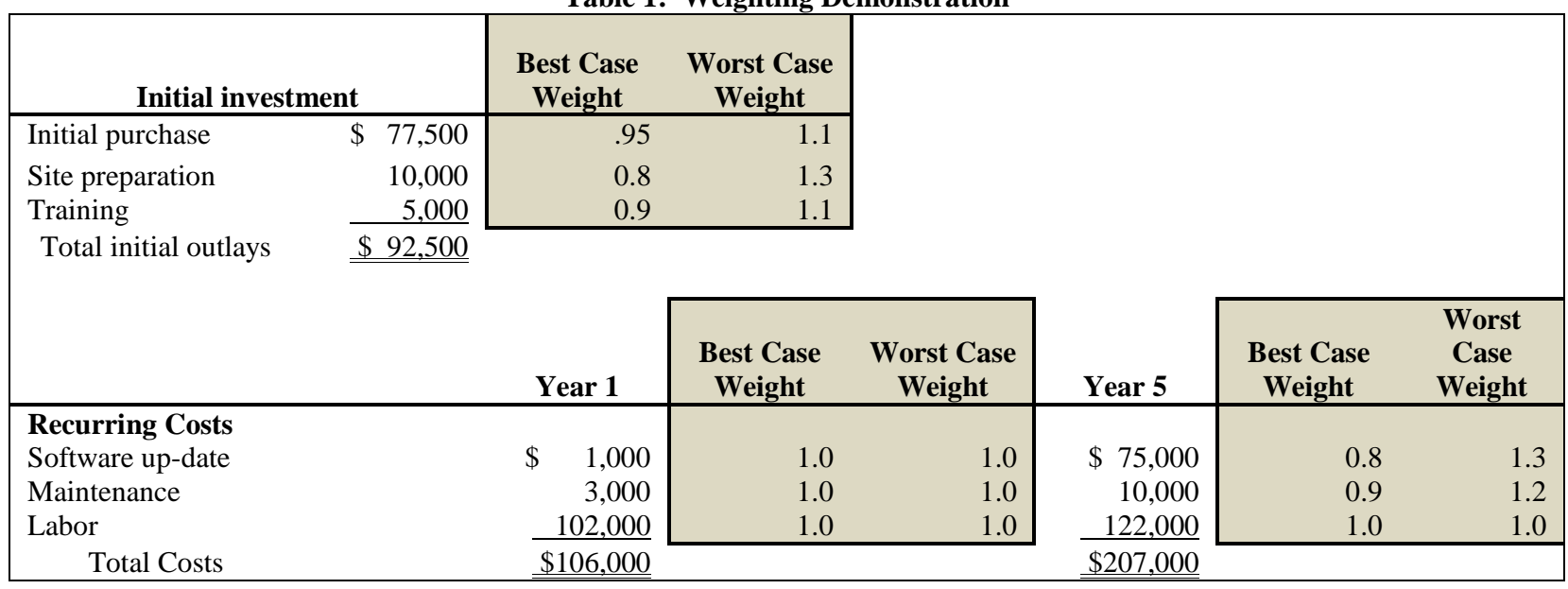

Table 2: Lease Component of the Lease vs. Purchase Decision

\section{Medical Arts Technology Institute \\ "Lease" Capital Budgeting NPV Analysis Data Section}

Cost of Capital $\quad 8 \%$

Investment Savings and Costs

\begin{tabular}{|c|c|c|c|}
\hline Initial outl & & $\begin{array}{c}\text { Best Case } \\
\text { Weight } \\
\end{array}$ & $\begin{array}{c}\text { Worst } \\
\text { Case } \\
\text { Weight }\end{array}$ \\
\hline \multicolumn{2}{|l|}{ Equipment purchase } & & \\
\hline Site preparation & $\$ 50,000$ & 1.0 & 1.0 \\
\hline Training & 5,000 & 1.0 & 1.0 \\
\hline First lease payment & 93,000 & 1.0 & 1.0 \\
\hline Other & - & 1.0 & 1.0 \\
\hline Other & - & 1.0 & 1.0 \\
\hline
\end{tabular}

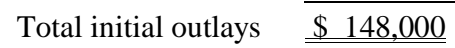

\begin{tabular}{|c|c|c|c|c|c|c|}
\hline & Year 1 & $\begin{array}{c}\text { Best Case } \\
\text { Weight }\end{array}$ & $\begin{array}{c}\text { Worst Case } \\
\text { Weight }\end{array}$ & Year 5 & $\begin{array}{c}\text { Best Case } \\
\text { Weight }\end{array}$ & $\begin{array}{c}\text { Worst Case } \\
\text { Weight }\end{array}$ \\
\hline $\begin{array}{l}\text { Recurring Costs } \\
\text { Software up-date } \\
\text { Maintenance }\end{array}$ & $\$$ & $\begin{array}{l}1.0 \\
1.0\end{array}$ & $\begin{array}{l}1.0 \\
1.0\end{array}$ & $\begin{array}{r}\$ 75,000 \\
10,000\end{array}$ & $\begin{array}{l}0.9 \\
0.9\end{array}$ & $\begin{array}{l}1.1 \\
1.1\end{array}$ \\
\hline Other & & 1.0 & 1.0 & & 1.0 & 1.0 \\
\hline Lease payment & 93,000 & 1.0 & 1.0 & & 1.0 & 1.0 \\
\hline $\begin{array}{l}\text { Other } \\
\text { Other }\end{array}$ & & $\begin{array}{l}1.0 \\
1.0\end{array}$ & $\begin{array}{l}1.0 \\
1.0\end{array}$ & - & $\begin{array}{l}1.0 \\
1.0\end{array}$ & $\begin{array}{l}1.0 \\
1.0\end{array}$ \\
\hline Total Costs & $\underline{\$ 93,000}$ & & & $\underline{\$ 85,000}$ & & \\
\hline
\end{tabular}

\section{Savings}

Other

Terminal value Total Savings

Tax Rate

Depreciation data

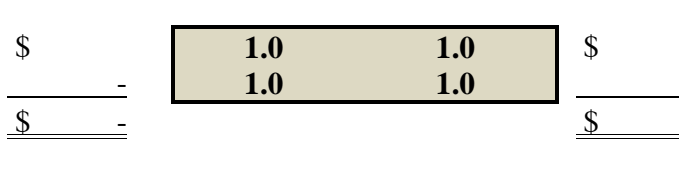

MACRS with half year convention

\begin{tabular}{ll}
1.0 & 1.0 \\
\hline
\end{tabular}

$20 \%$

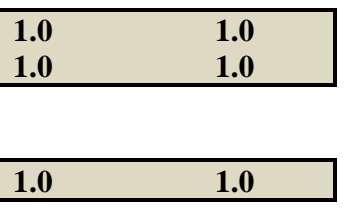

Years 
Medical Arts Technology Institute

"Purchase" Capital Budgeting Analysis Data Section

Cost of Capital

$8 \%$

Investment Savings and Costs

\begin{tabular}{|c|c|c|c|}
\hline Initial outlay & costs & $\begin{array}{c}\text { Best Case } \\
\text { Weight }\end{array}$ & $\begin{array}{c}\text { Worst } \\
\text { Case } \\
\text { Weight } \\
\end{array}$ \\
\hline Equipment purchase & $\$ 425,000$ & 1.0 & 1.0 \\
\hline Site preparation & 50,000 & 0.9 & 1.1 \\
\hline Training & 5,000 & 0.9 & 1.1 \\
\hline Other & - & 1.0 & 1.0 \\
\hline Other & - & 1.0 & 1.0 \\
\hline Other & - & 1.0 & 1.0 \\
\hline
\end{tabular}

Total initial outlays $\underline{\underline{\$ 525,000}}$

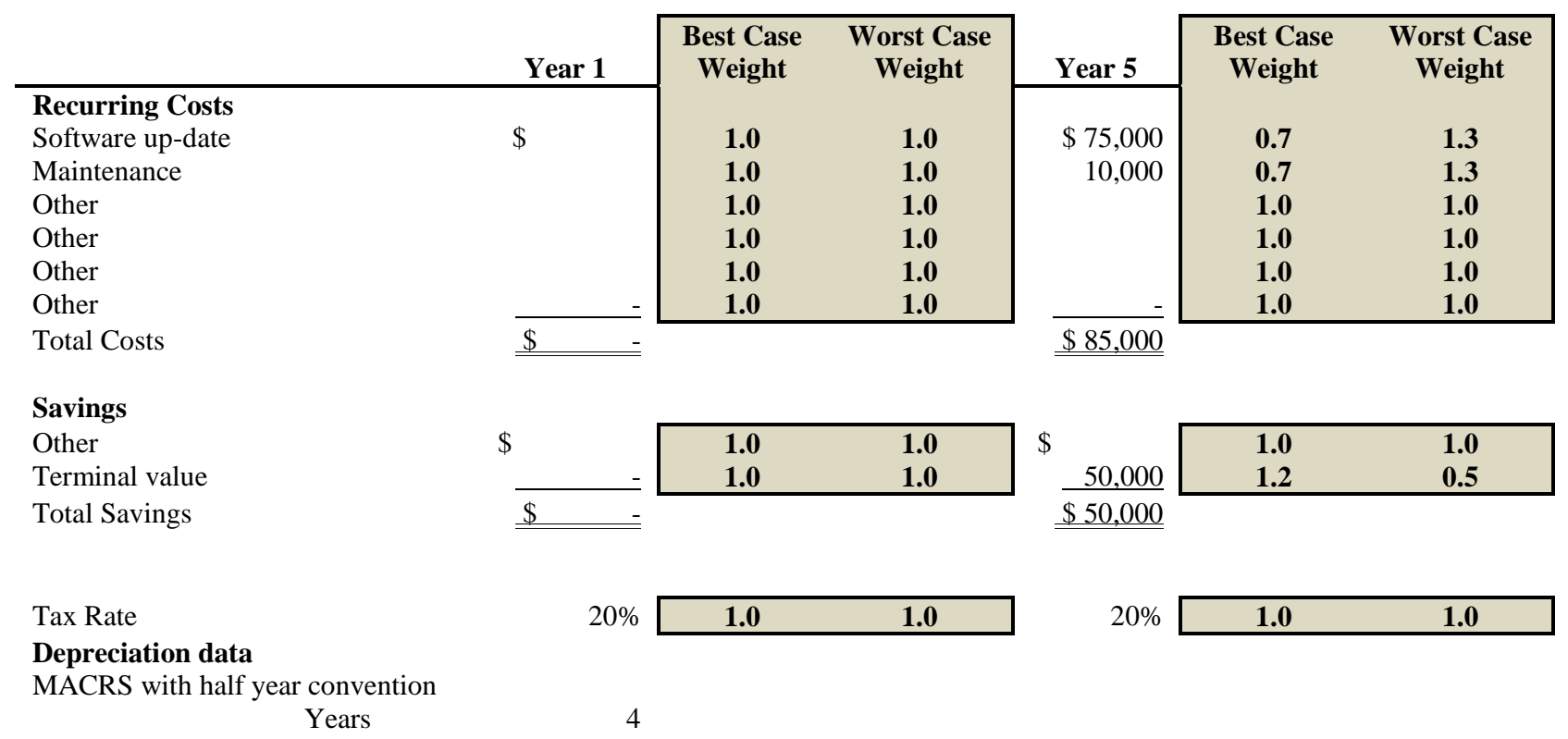


Figure 3: Lease vs. Purchase Distributions

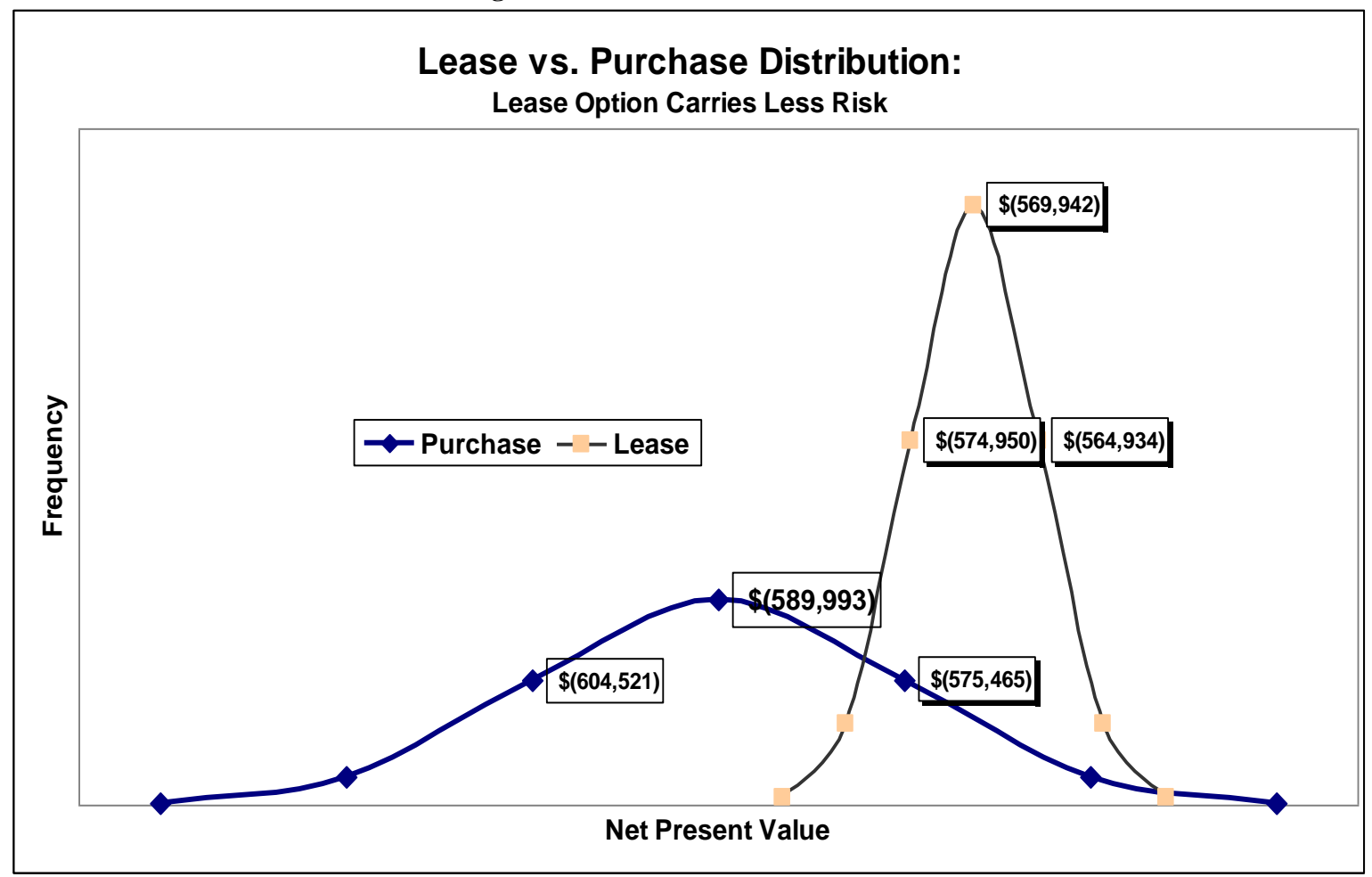

${ }^{1}$ Davis, I. and Stephenson, E. 2006. Ten trends to watch in 2006. The McKinsey Quarterly (Web exclusive) January.

${ }^{2}$ Graham, J. and Harvey, C. 2002. How Do CFO's Make Capital Budgeting and Capital Structure Decisions? Journal of Applied Corporate Finance, 15(1): 8-23.

${ }^{3}$ Ryan, P.A. and Ryan, G.P. 2002. Capital Budgeting Practices of the Fortune 1000: How Have Things Changed? Journal of Business and Management, 8(4): 355-364.

${ }^{4}$ Shapiro, A.C. 2005. Capital Budgeting and Investment Analysis. Prentice Hall, Upper Saddle River, New Jersey. 


\section{NOTES}

